\title{
Ensino da adição e subtração baseado no Campo Aditivo: uma proposta na Cultura Digital
}

\author{
Crediné S. de Menezes ${ }^{1}$, Genilson Gomes Corradi ${ }^{2}$ \\ ${ }^{1}$ Universidade Federal do Rio Grande do Sul (UFRGS) - Departamento de Estudos \\ Básicos - Av Paulo Gama, 110, Farroupilha, Porto Alegre - RS \\ ${ }^{2}$ Universidade Federal do Espírito Santo (UFES) - Departamento de Informática - \\ Vitória - ES \\ \{credine, ggcorradi\} @gmail.com
}

\begin{abstract}
Researches of evaluation about learning has shown that students, at the beginning of their student life, have a great deal of difficulty in learning the contents of the subject of mathematics, especially the basic operations of addition/ subtraction and multiplication / division. In the Theory of Conceptual Fields, created by the French researcher Gérard Vergnaud, two pedagogical approaches are proposed to facilitate the learning of these operations, but their use is a difficult task for teachers. This work investigates these difficulties with teachers of a teaching network and proposes a digital environment to support the teaching and learning of operations of addition and subtraction in a collaborative and ubiquitous way.
\end{abstract}

Resumo. As pesquisas de avaliação da aprendizagem tem mostrado que os alunos, no início da sua vida estudantil, tem muita dificuldade na aprendizagem dos conteúdos da disciplina de matemática, em especial, das operações básicas de soma/subtração e multiplicação/divisão. Na Teoria dos Campos Conceituais, criada pelo pesquisador Francês Gérard Vergnaud são propostas duas abordagens pedagógicas para facilitar a aprendizagem destas operações, porém a sua utilização é uma tarefa difícil para os professores. Este trabalho investiga estas dificuldades junto a professores de uma rede de ensino e propõe um ambiente digital para apoiar o ensino e a aprendizagem das operações de adição e subtração de forma colaborativa e ubiqua.

\section{Introdução}

O ensino da matemática sempre se apresentou como um grande desafio, fato que é comprovado pelas pesquisas de avaliação da aprendizagem como o SAEB (Sistema de Avaliação da Educação Básica) de 2017, principal intrumento de avaliação da Educação Básica.

Em matemática alguns conteúdos são fundamentais e o domínio deles pode abrir portas para a aprendizagem de muitos outros. Dentre estes conteúdos, encontra-se o conceito das operações básicas de adição/subtração e multiplicação/divisão. Estas operações geralmente são ensinadas usando os métodos tradicionais que enfatiza apenas a memorização das operações e a aplicação do algoritmo de cálculo.

Uma nova forma de ensinar matemática para as operações de adição/subtração e multiplicação/divisão, baseada na Teoria dos Campos Conceituais [Vergnaud 1982], foi criada pelo pesquisador francês Gérard Vergnaud. Para o ensino de adição e subtração 
VIII Congresso Brasileiro de Informática na Educação (CBIE 2019)

Anais do XXV Workshop de Informática na Escola (WIE 2019)

ele criou uma abordagem pedagógica chamada Campo Aditivo. Esta abordagem já é utilizada por várias redes de ensino no Brasil que usam materiais concretos (figurinhas, bolas de gudes, etc) para auxiliar os alunos no processo de contagem para a resolução das situações-problemas. Entretanto, em função do grande número de alunos nas salas de aula e a quantidade de tarefas que um professor precisa realizar para usar estas abordagens, é constatado que ele nem sempre consegue dar atenção individualizada e personalizada aos alunos, o que dificulta um trabalho eficiente com esta abordagem.

Dentro deste contexto, este artigo investiga as principais dificuldades levantadas com professores de uma rede de ensino na aplicação do Campo Aditivo, e propõe um ambiente digital para apoiar o processo de ensino e aprendizagem baseado nesta abordagem pedagógica. Foi construido um protótipo que foi testado em duas escolas para turmas do Ensino Fundamental.

\section{Procedimentos metodológicos e o contexto da pesquisa}

Todo o desenho do ambiente proposto foi baseado em entrevistas feitas com os professores que apresentaram suas dificuldades, necessidades e dicas sobre a estratégia pedagógica mais adequada ao ensino de crianças na faixa etária de 8 a 10 anos para o ensino das operações de adição e subtração baseado no Campo Aditivo.

O ambiente digital definido tinha como principais objetivos: auxiliar o professor no processo de ensino das operações básicas de matemática, simplificando seu trabalho e permitindo um atendimento mais individualizado aos alunos através do mapeamento de suas dificuldades e apoiar os alunos na aprendizagem destas operações.

A pesquisa, realizada em duas escolas com um público de 61 alunos e 3 professores, se baseou na observação do autor sobre a aplicação de instrumentos de avaliação da aprendizagem (em papel e computador) para validação da proposta do ambiente concebido e do protótipo construido. As etapas da pesquisa são mostradas na Tabela 1:

Tabela 1. Etapas da pesquisa realizada

\begin{tabular}{|c|l|}
\hline Etapa & Descrição da atividade \\
\hline 1 & $\begin{array}{l}\text { Aplicação de avaliação da aprendizagem de adição e subtração (instrumento papel) } \\
\text { com 16 situações-problemas; }\end{array}$ \\
\hline 2 & $\begin{array}{l}\text { Tabulação das respostas dos alunos no instrumento papel de acordo com os } \\
\text { critérios definidos pelo pesquisador; }\end{array}$ \\
\hline 3 & $\begin{array}{l}\text { Aplicação de avaliação da aprendizagem de adição e subtração (instrumento } \\
\text { computador) com 16 situações problemas usando o ambiente digital prototipado; }\end{array}$ \\
\hline 4 & $\begin{array}{l}\text { Tabulação das respostas na ferramenta no computador de acordo com os critérios } \\
\text { definidos pelo pesquisador; }\end{array}$ \\
\hline 5 & $\begin{array}{l}\text { Aplicação de questionário aos professores para que apresentassem sua percepção } \\
\text { sobre o experimento; }\end{array}$ \\
\hline 6 & Análise dos resultados e socialização com os professores da escola. \\
\hline
\end{tabular}

\section{Ambiente proposto}

A figura 1 mostra o fluxo simplificado do ambiente proposto, cuja síntese de cada etapa é descrita abaixo. 
VIII Congresso Brasileiro de Informática na Educação (CBIE 2019)

Anais do XXV Workshop de Informática na Escola (WIE 2019)

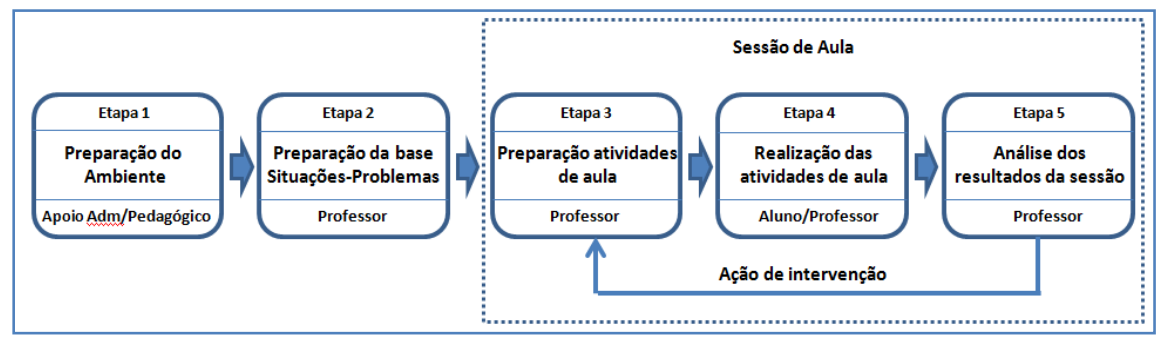

Figura 1: Fluxo simplificado do funcionamento do ambiente digital. Fonte: Os Autores

Etapa 1: Preparação do ambiente (Apoio Administrativo/Pedagógico) - cadastramento das as configurações gerais do ambiente digital e as relações do Campo Aditivo.

Etapa 2: Preparação da base de Situações-Problemas (Professor) - cadastramento das informações necessárias para a geração das situações-problemas e a geração das situações-problemas para o Campo Aditivo.

Etapa 3: Preparação das atividades de aula (Professor) - geração das sessões de exercícios que serão submetidas aos alunos (Figura 2).

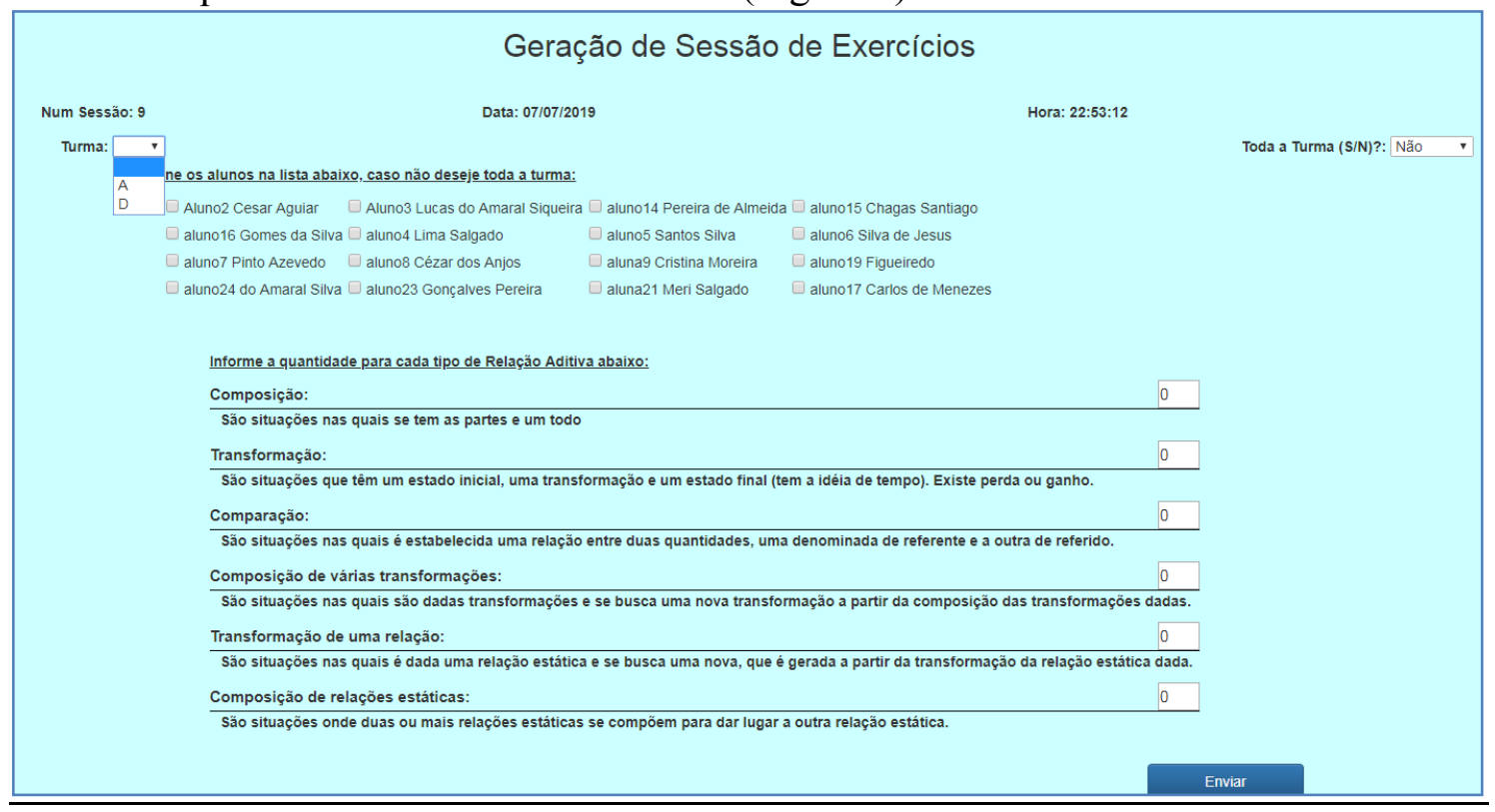

Figura 2: Funcionalidade de Geração de sessão de exercícios para o Campo Aditivo. Fonte: Os Autores

Etapa 4: Realização das atividades de aula(Aluno/Professor) - resolução das situaçõesproblemas pelos alunos enquanto o professor monitora, usando um painel de acompanhamento, a resolução por cada aluno e pode fazer alguma assistência aos alunos (Figura 3). 
VIII Congresso Brasileiro de Informática na Educação (CBIE 2019)

Anais do XXV Workshop de Informática na Escola (WIE 2019)

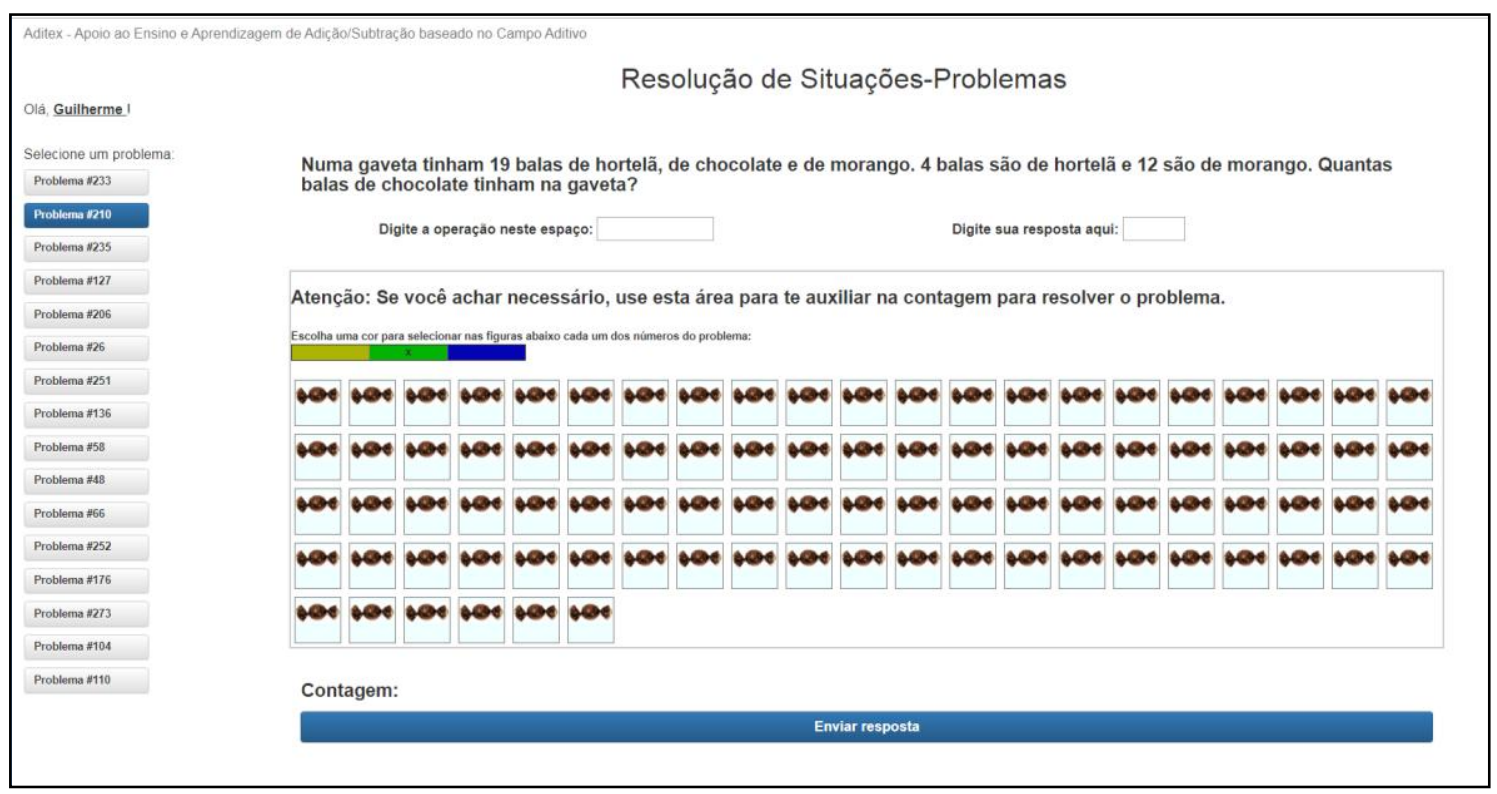

Figura 3: Funcionalidade de Resolução de situações-problemas do Campo Aditivo. Fonte: Os Autores

Etapa 5: Análise dos resultados da sessão (Professor) - Nesta etapa o professor gera novas sessões personalizadas de acordo com as informações fornecidas pela ferramenta com base na resolução dos alunos (remediação com base no erro).

\section{Análise e dicussão dos resultados}

As 16 situações-problemas apresentadas para os alunos contemplavam todos os raciocíonios das relações aditivas de Composição, Transformação e Comparação. As situações-problemas do instrumento papel eram diferentes das resolvidas no ambiente digital, porém similares em raciocínio e complexidade.

O intervalo entre a aplicação em papel e computador foi de no mínimo 2 dias para cada turma para que os racicíonios não ficassem tão presentes na mente dos alunos. Um resumo dos resultados é apresentado na Tabela 2.

Tabela 2: Resultados da aplicação da pesquisa nas 3 turmas Fonte: Os Autores

\begin{tabular}{|c|c|c|c|}
\hline \multirow{2}{*}{$\begin{array}{c}\text { Ano } \\
\text { Escolar }\end{array}$} & \multirow{2}{*}{ Item da avaliação } & \multicolumn{2}{|c|}{ Instrumento } \\
\hline & & Papel & Computador \\
\hline \multirow{5}{*}{$3 \circ$ ano } & Quantidade de alunos que participaram da pesquisa & 19 & 18 \\
\hline & Quantidade de situações-problemas aproveitados ${ }^{(1)}$ & 256 & 256 \\
\hline & Quantidade de situações-problemas não resolvidos & 27 & $50^{(2)}$ \\
\hline & Quantidade respostas incorretas & 129 & 115 \\
\hline & Percentual de acerto & $29,30 \%$ & $40,63 \%$ \\
\hline \multirow{5}{*}{ 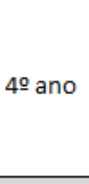 } & Quantidade de alunos que participaram da pesquisa & 21 & 21 \\
\hline & Quantidade de situações-problemas resolvidos & 336 & 336 \\
\hline & Quantidade de situações-problemas não resolvidos & 16 & 0 \\
\hline & Quantidade respostas incorretas & 140 & 117 \\
\hline & Percentual de acerto & $53,57 \%$ & $63,99 \%$ \\
\hline \multirow{5}{*}{50 ano } & Quantidade de alunos que participaram da pesquisa & 24 & 24 \\
\hline & Quantidade de situações-problemas resolvidos & 384 & 384 \\
\hline & Quantidade de situações-problemas não resolvidos & 0 & 4 \\
\hline & Quantidade respostas incorretas & 59 & $105^{(3)}$ \\
\hline & Percentual de acerto & $78,91 \%$ & $71,88 \%$ \\
\hline
\end{tabular}


VIII Congresso Brasileiro de Informática na Educação (CBIE 2019)

Anais do XXV Workshop de Informática na Escola (WIE 2019)

Notas:

(1) Somente foram aproveitados os alunos que responderam nos 2 intrumentos. No caso do $3^{\circ}$ ano, foram 16 alunos. Nas demais turmas, todos resolveram nos 2 intrumentos.

(2) Este número foi elevado pois a funcionalidade possuia uma regra de envio sem nenhum preenchimento que gerou confusão para os alunos.

(3) Este número foi alto pois alguns alunos tentaram resolver fazendo "conta de cabeça" e erraram pois não aceitaram usar o recurso de apoio à contagem disponivel na ferramenta.

Os resultados e a percepção dos professores expressas nos questionários evidenciam que o ambiente digital proposto promoveu melhoria da aprendizagem para os alunos de forma geral.

\section{Considerações Finais}

A proposta do ambiente digital é de apoiar o professor no processo de ensino das operações de adição e subtração baseado no Campo Aditivo e auxiliar os alunos na aprendizagem dos conceitos envolvidos nesta operação. Com base nos resultados das aplicações e nas respostas dos professores através do questionário aplicado ficou evidenciado que o ambiente digital proposto foi bem aderente ao $3^{\circ}$ e $4^{\circ}$ ano, pois promoveu aumento na quantidade de acertos por parte dos alunos. Com relação ao $5^{\circ}$ ano, entendemos que este ambiente digital precisa ser melhorado, em especial, no recurso de auxílio à contagem que está implementado de forma não muito adequada para situações-problemas com números grandes, fazendo com que os alunos "chutem" o resultado das operações, incorrendo em erro (foi o que aconteceu). Os professores elogiaram na ferramenta a possibilidade de geração de sessões de exercícios específicas para alunos com base no resultado da sessão anterior e a correção automática com o rastro do raciocínio usado pelos alunos na resolução das situações-problemas.

Desta forma, entendemos que a construção deste ambiente digital conforme concebido será uma grande contribuição para o aumento proficiência dos alunos em matemática, melhorando os resultados nas pesquisas de avaliação de aprendizagem, em especial, do Ensino Fundamental.

\section{Referências}

Etcheverria, Teresa Cristina. O Ensino das Estruturas Aditivas junto a Professoras dos Anos Iniciais do Ensino Fundamental. 2014. 252 f. Diss. Tese (Doutorado em Educação Matemática, Área de concentração: Ensino e Aprendizagem em Matemática e suas Inovações)-Universidade Anhanguera de São Paulo, São Paulo, SP, 2014.

Santana, Eurivalda, Alex Andrade Alves, and Célia Barros Nunes. "A Teoria dos Campos Conceituais num Processo de Formação Continuada de Professores." Bolema: Boletim de Educação Matemática 29.53 (2015): 1162-1180.

Vergnaud, Gérard. "Psicología Cognitiva e do Desenvolvimento e Pesquisas em Educação Matemática: Algumas questões teóricas e metodológicas. Trad. de Weiss, J. Apresentação concedida para o grupo Canadense de Estudos em Educação Matemática na Queen'se University, Kingston, jun.1982. 